\title{
Penerapan Fitur 3D Maps pada Aplikasi Virtual Tour sebagai Media Promosi Wisata Qubu Resort
}

\author{
Nanda Tamara Ananraytama ${ }^{\# 1}$, Novi Safriadi ${ }^{\sharp 2}$, Helen Sasty Pratiwi ${ }^{\# 3}$ \\ "Program Studi Informatika Universitas Tangjungpura \\ Jl. Prof. Dr. H. Hadari Nawawi, Kota Pontianak, 78115 \\ ${ }^{1}$ ntananrayatama@gmail.com \\ ${ }^{2}$ safriadieinformatics.untan.ac.id \\ 3helensastypratiwi@informatics.untan.ac.id
}

\begin{abstract}
Abstrak- Qubu Resort adalah taman wisata bertempat di Kabupaten Kubu Raya. Tempat wisata ini telah diliput oleh berbagai media, baik media cetak maupun situs berita online. Namun, dari sekian banyak hasil liputan media, sebagian besar ditampilkan dalam bentuk teks dan gambar. Hal ini membatasi pengunjung untuk lebih mengenal lingkungan tempat wisata. Berdasarkan kondisi dan permasalahan yang ada, maka diperlukan pengembangan teknologi, yaitu dengan menggunakan virtual tour dengan fitur 3D maps. Aplikasi dibangun berbasis website. Tujuan dari aplikasi adalah untuk membantu pengunjung dalam memperoleh informasi mengenai tempat wisata di Qubu Resort. Virtual tour yang dimuat menampilkan foto panorama dengan sudut pandang $360^{\circ} \times 180^{\circ}$, sedangkan bangun 3D berfungsi untuk merepresentasikan denah lokasi Qubu Resort. Penelitian ini menggunakan metode pengembangan aplikasi multimedia MDLC (Multimedia Development Life Cycle) yang terdiri atas 6 tahap, yaitu Concept, Design, Material Collecting, Assembly, Testing, dan Distribution. Pengujian aplikasi terdiri dari beberapa aspek. Pada pengujian aspek compatibility, aplikasi berhasil diakses pada tiga perangkat komputer berbeda dan komponen pada website dapat ditampilkan dengan baik. Pada pengujian aspek usability, aplikasi dinilai sangat positif dengan total persentase $85,1 \%$. Serta pada pengujian aspek portability, yang menunjukan aplikasi lebih baik jika diakses menggunakan browser berbasis desktop.
\end{abstract}

Kata kunci- Qubu Resort, Virtual Tour, 3D Maps, MDLC

\section{PEndahuluan}

Qubu Resort adalah taman wisata yang terintegrasi dan berbasis pada lingkungan, budaya, dan pemberdayaan masyarakat bertempat di Kabupaten Kubu Raya. Qubu Resort dilengkapi dengan berbagai objek wisata, misalnya ParadisQ Waterpark yang merupakan wahana air terbesar di Kalimantan Barat, serta berbagai fasilitas penunjang lainnya. Qubu Resort telah diliput oleh berbagai media, baik media cetak maupun situs berita online. Namun, dari berbagai hasil liputan media yang ada, informasi yang ditampilkan masih berupada teks dan gambar.
Berdasarkan kondisi dan permasalahan yang ada, maka diperlukan pengembangan teknologi yang lebih inovatif dan komunikatif. Adapun teknologi yang dapat digunakan adalah dengan memanfaatkan teknologi virtual tour. Aplikasi dibangun berbasis website, agar dapat lebih mudah diakses oleh pengguna.

Virtual tour yang akan ditampilkan memuat tampak nyata area wisata dalam bentuk foto panorama dengan sudut pandang $360^{\circ} \times 180^{\circ}$. Aplikasi juga memuat fitur 3D Maps, yaitu berupa bangun 3D yang berfungsi untuk merepresentasikan denah lokasi Qubu Resort. Melalui aplikasi yang akan dibuat, pengunjung dapat melihat lingkungan yang ada secara lebih nyata, melalui dunia maya.

\section{URAIAN PENELITIAN}

\section{A. Virtual Tour}

Virtual tour atau disebut juga panoramic tour adalah sebuah simulasi dari suatu tempat yang benar-benar ada, biasanya terdiri dari kumpulan foto-foto panorama, kumpulan gambar yang terhubung oleh hyperlink, ataupun video, dan/atau virtual model dari lokasi yang sebenarnya. Bisa juga menggunakan unsur-unsur multimedia lainnya seperti efek suara, musik, narasi, dan tulisan [1].

Istilah virtual tour sering diasosiasikan dengan virtual tour yang diciptakan dengan kamera foto yang tidak bergerak dan dibuat dari sejumlah foto yang diambil dari sebuah titik pivot [2]. Virtual tour digunakan untuk memudahkan user dalam melihat suatu lingkungan tanpa harus secara fisik melakukan perjalanan ke lokasi tersebut. Dalam penggunaanya, virtual tour diharuskan berbasis web sehingga dapat diakses dimana saja dan kapan saja [3]

\section{B. Pemodelan $3 D$}

3D (tiga dimensi) adalah objek atau ruang yang memiliki panjang, lebar, dan tinggi yang memiliki bentuk. Konsep tiga dimensi menunjukan sebuah objek atau ruang yang memiliki tiga dimensi geometris terdiri dari kedalaman, lebar, dan 
tinggi. Contoh tiga dimensi suatu objek atau benda adalah bola, piramida, atau benda spasial seperti kotak sepatu [4].

Istilah "3D" juga (dan salah) yang digunakan (terutama bahasa Inggris) untuk menunjukkan representasi dalam grafis komputer (digital), dengan cara menghilangkan gambar stereoscopic atau gambar lain dalam pemberian bantuan, dan bahkan efek stereo sederhana, yang secara konstruksi membuat efek 2D (dalam perhitungan proyeksi perspektif, shading) [5].

\section{Metode Pengembangan Aplikasi Multimedia}

Metode yang digunakan dalam pengembangan aplikasi multimedia adalah Multimedia Development Life Cycle (MDLC). Menurut Luther, ada enam tahap dalam pengembangan multimedia, yaitu konsep (concept), perancangan (design), pengumpulan bahan (material collecting), pembuatan (assembly), pengujian (testing), dan distribusi (distribution). Harus dimulai dari concept dan diakhiri dengan tahap distribution, sedangkan tahap material collecting dapat dikerjakan secara parallel dengan tahap assembly. Metodologi ini sangat cocok digunakan untuk aplikasi berbasis multimedia karena keenam tahap bisa merangkum semua yang diperlukan untuk mengembangkan aplikasi multimedia [6].

1. Konsep (Concept)

Tahap konsep (concept), yaitu ide (gagasan), sinopsis, treatment dan menentukan tujuan, termasuk identifikasi audiens (pihak yang bersangkutan).

2. Perancangan (Design)

Perancangan (design) adalah membuat spesifikasi secara rinci mengenai arsitektur proyek, gaya, dan kebutuhan material untuk proyek.

3. Pengumpulan Bahan (Material Collecting)

Pada tahap pengumpulan bahan (material collecting), dilakukan pengumpulan bahan, seperti clipart image, animasi, dan audio, berikut pembuatan gambar grafik, foto dan lain-lain yang diperlukan untuk tahap berikutnya.

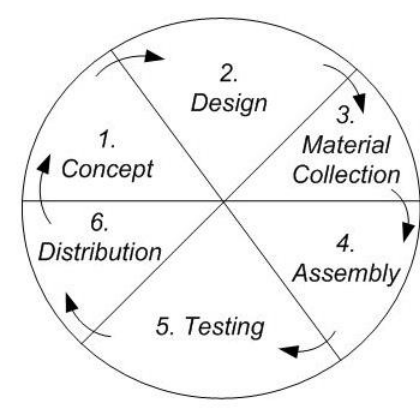

Gambar. 1 Metodologi Pengembangan Aplikasi Multimedia

4. Pembuatan (Assembly)

Tahap pembuatan (assembly), merupakan tahap dimana seluruh objek multimedia dibuat. Pembuatan aplikasi berdasarkan storyboard dan struktur navigasi yang berasal dari tahap design.

\section{Pengujian (Testing)}

Tahap pengujian (testing), dilakukan setelah selesai tahap pembuatan dan seluruh data maupun komponen multimedia telah dimasukkan. Fungsi dari pengujian adalah memastikan bahwa hasil pembuatan aplikasi multimedia sesuai dengan yang direncanakan.

6. Distribusi (Distribution)

Bila aplikasi multimedia akan digunakan dengan mesin yang berbeda, penggandaan menggunakan floppy disk, CD-ROM, tape atau distribusi dengan jaringan sangat diperlukan.

\section{METODOLOGI PENELITIAN}

Aplikasi yang akan dibangun merupakan sebuah perangkat lunak yang dapat digolongkan sebagai aplikasi berbasis multimedia, karena menggunakan foto panorama dan bangun 3D sebagai data utama dalam penelitian. Oleh karena itu, pada penelitian ini digunakan metode untuk pengembangan aplikasi multimedia, yaitu Multimedia Development Life Cycle atau MDLC. Metodologi MDLC yang digunakan bersumber pada Luther yang dibahas oleh Sutopo (2003). MDLC terdiri dari enam tahapan dasar, yaitu konsep (concept), perancangan (design), pengumpulan bahan (material collecting), pembuatan (assembly), pengujian (testing), dan distribusi (distribution).

\section{A. Konsep (Concept)}

Aplikasi yang akan dibangun merupakan sebuah perangkat lunak berbasis website yang dibangun secara dinamis, sehingga pengguna dari aplikasi terdiri dari 2 pengguna, yaitu pengunjung website (user) dan pengelola website (admin). Tujuan dari aplikasi adalah sebagai alat bantu bagi pengunjung untuk lebih mengenal objek wisata yang ada, serta sebagai media promosi wisata untuk meningkatkan daya tarik wisatawan.

Pada halaman utama website user terdapat informasi tentang aplikasi yang telah dibuat dalam bentuk teks dan gambar, serta menu navigasi untuk mengarahkan pengunjung ke halaman Virtual Tour dan 3D Maps. Virtual tour yang akan ditampilkan memuat tampak nyata area wisata dalam bentuk foto panorama dengan sudut pandang $360^{\circ}$ x $180^{\circ}$, sedangkan fitur 3D Maps yang ditampilkan berfungsi untuk merepresentasikan denah lokasi Qubu Resort.

\section{B. Perancangan (Design)}

Perancangan dilakukan untuk menggambarkan kebutuhan sistem, alur kerja aplikasi, serta hasil akhir yang diharapkan dari aplikasi yang dibuat.

1. Perancangan Arsitektur Sistem

Arsitektur Sistem adalah suatu pemetaan atau rencana kebutuhan-kebutuhan informasi di dalam suatu organisasi. Arsitektur berguna sebagai penuntun bagi operasi sekarang atau menjadi cetak biru (blueprint) untuk arahan dimasa mendatang [7]. 
Aplikasi yang akan dibangun merupakan aplikasi berbasis website dan terdiri dari 2 pengguna, yaitu admin dan user. Berikut adalah cara kerja sistem.

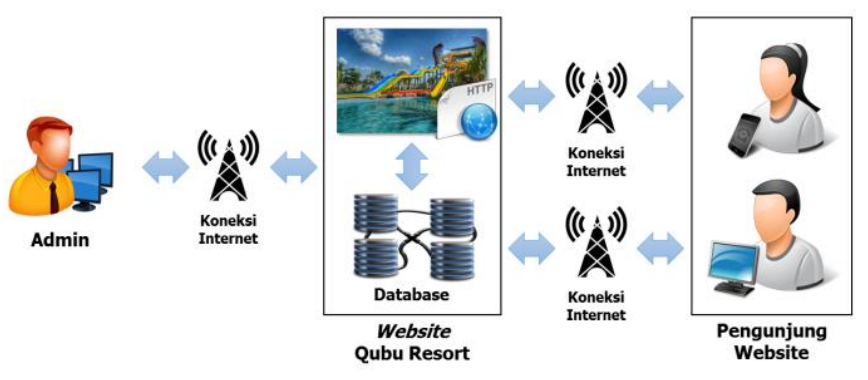

Gambar. 1 Perancangan Arsitektur Sistem

2. Flowchart

Flowchart atau diagram alir yang dibuat merupakan gambaran tentang alur aplikasi berdasarkan komponen virtual tour dan denah lokasi 3D yang akan dibuat.

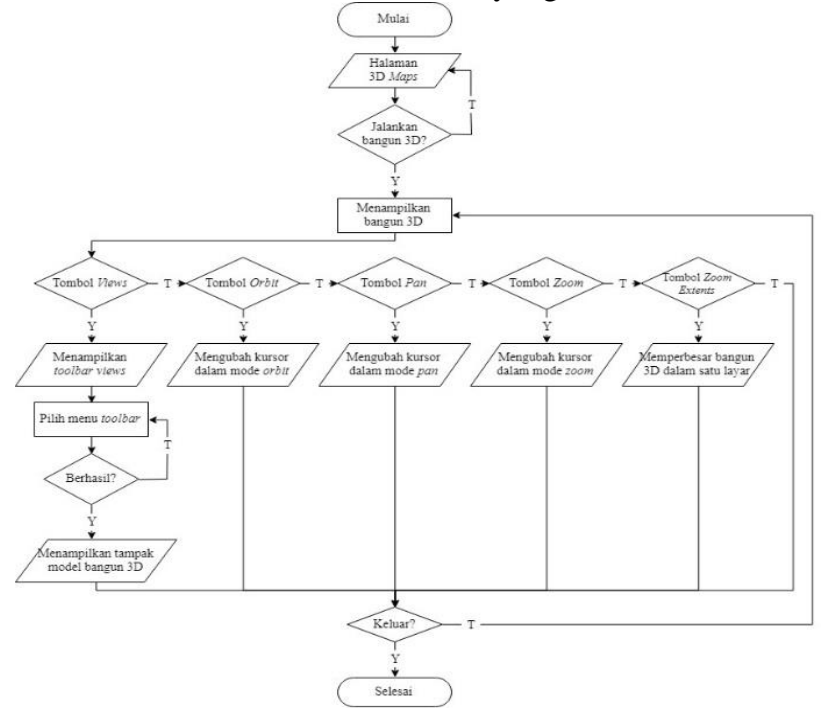

Gambar. 3 Flowchart Fitur 3D Maps

3. Perancangan Antarmuka Pengguna

Antarmuka pengguna adalah bagian dari program yang mengadakan interaksi dengan pengguna [8]. Aplikasi yang akan dibangun terdiri dari dua pengguna akhir, yaitu admin sebagai pihak yang memiliki hak akses untuk memanajemen data dan user sebagai pengunjung website.

a. Struktur Antarmuka User

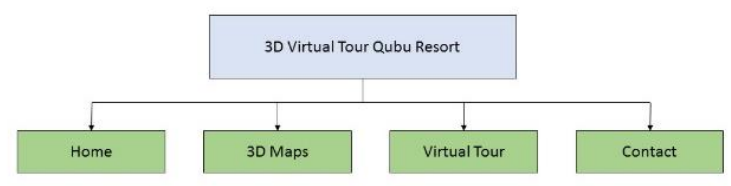

Gambar. 4 Struktur Antarmuka User

\section{b. Struktur Antarmuka Admin}

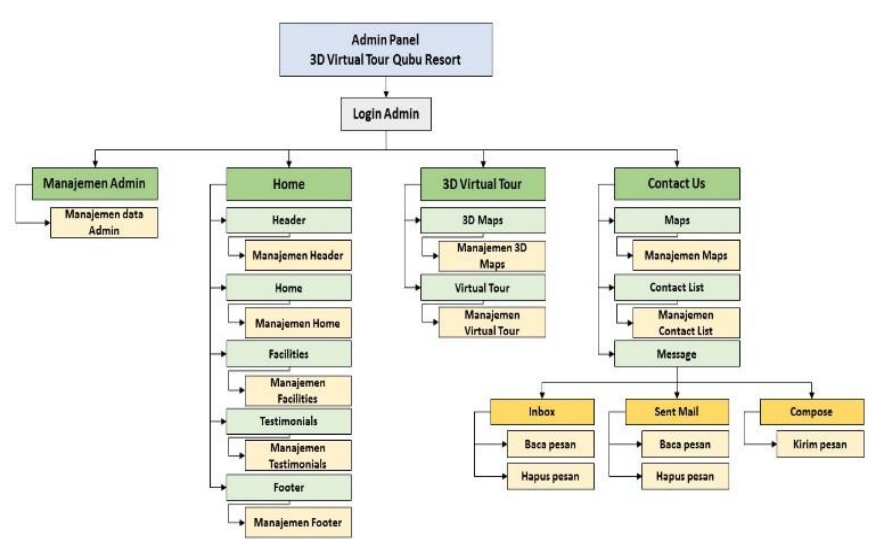

Gambar. 5 Struktur Antarmuka Admin

\section{Pengumpulan Bahan (Material Collecting)}

Setelah melakukan perancangan, maka selanjutnya adalah tahap pengumpulan bahan (material collecting). Berdasarkan dari cara memperolehnya, data yang dibutuhkan dalam penelitian ini dibagi menjadi dua, yaitu data primer dan data sekunder.

Adapun yang menjadi data primer dalam penelitian ini adalah gambar panorama $360^{\circ}$ × $180^{\circ}$ yang diperoleh dengan cara mengambil gambar secara langsung ke lokasi wisata Qubu Resort pada beberapa area, yaitu gerbang masuk Qubu Resort, area parkiran, Souvenir Shop, Food Corner, serta area ParadisQ Waterpark. Pada masing-masing titik lokasi, diambil empat foto secara horizontal, yaitu depan $\left(0^{\circ}\right)$, kanan $\left(90^{\circ}\right)$, belakang $\left(180^{\circ}\right)$, dan kiri $\left(270^{\circ}\right)$, serta secara vertikal, yaitu atas $\left(0^{\circ}\right)$ dan bawah $\left(180^{\circ}\right)$. Untuk fitur 3D Maps, data yang dibutuhkan berupa denah lokasi dasar dalam bentuk 2D sebagai acuan dalam pembuatan bangun 3D.

Data sekunder diperoleh dari hasil studi kepustakaan sebagai bahan referensi mengenai teori-teori yang mendukung penelitian. Studi pustaka dilakukan dengan cara membaca dan memahami materi-materi yang berhubungan dengan penelitian.

\section{HASIL PERANCANGAN DAN PENGUJIAN APLIKASI}

\section{Pembuatan (Assembly)}

Adapun langkah-langkah dalam tahap pembuatan aplikasi meliputi proses menyatukan gambar yang ada dengan Panoweaver untuk membuat panorama dan Touweaver menjadikan gambar tersebut sebuah aplikasi virtual tour, pembuatan denah lokasi dalam bentuk bangun 3D menggunakan aplikasi Google SketchUp, serta proses pengkodean website.

Virtual Tour yang ditampilkan memuat informasi berupa cara penggunaan aplikasi, denah lokasi, tombol navigasi, dan daftar panorama. Pada virtual tour juga terdapat narasi dalam bentuk suara untuk memberi deskripsi dan informasi 
mengenai panorama yang aktif. Pada masing-masing panorama terdapat tombol hotspot untuk user berpindah dari satu titik ke titik lain.

Halaman 3D Maps memuat denah lokasi Qubu Resort dalam bentuk bangun 3D. Denah yang ditampilkan dapat dilihat dan digerakan dari segala sisi dengan bantuan mouse atau touchpad. Untuk mempersebar dan memperkecil denah, dapat dilakukan dengan cara scroll pada bagian yang ingin dilihat lebih detail.
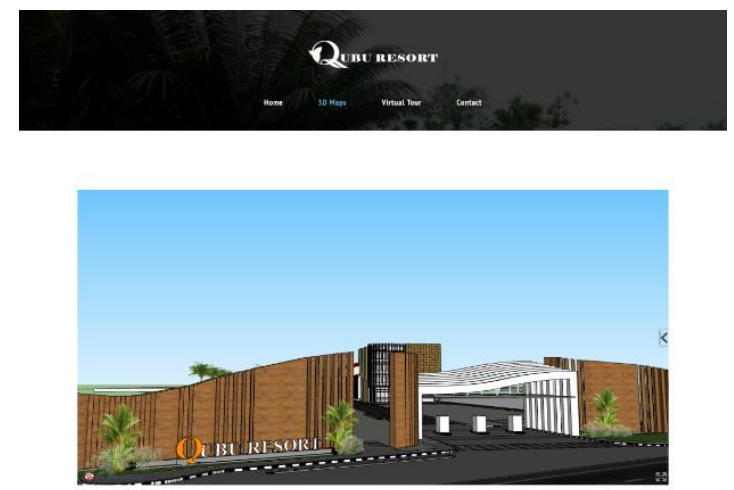

Gambar. 6 Tampilan Antarmuka 3D Maps

\section{E. Pengujian (Testing)}

Suatu perangkat lunak perlu dijaga kualitasnya, dimana kualitas bergantung pada kepuasan pelanggan [9]. Tahap pengujian (testing) dilakukan setelah aplikasi selesai dibuat. Pengujian aplikasi pada penelitian terdiri dari beberapa aspek.

1. Pengujian Compatibility

Tujuan dari pengujian ini adalah untuk mengukur sejauh mana produk kompatibel dengan produk lain dalam suatu lingkungan [10]. Pengujian dilakukan dengan cara mengakses halaman website dan melihat tampilan dari masing-masing halaman menggunakan komputer dengan spesifikasi dan sistem operasi berbeda.

TABEL I

SPESIFIKASI KOMPUTER

\begin{tabular}{|c|}
\hline Spesifikasi Komputer 1 \\
\hline Processor : Intel Pentium 987 $1.5 \mathrm{GHz}$ \\
Memori : 2048 MB \\
VGA : Intel HD Graphics \\
Sistem Operasi : Ubuntu 6.04.4 LTS 64-bit \\
\hline Spesifikasi Komputer 2 \\
\hline Processor $:$ Intel Core i7 $~ 2.9 \mathrm{GHz}$ \\
Memori : 16 GB RAM \\
VGA : Radeon Pro 560 4GB \\
Sistem Operasi : macOS High Sierra 64-bit \\
Spesifikasi Komputer 3 \\
\hline Processor $:$ Intel Core i7 2.0 GHz \\
Memori : 8192 MB RAM \\
VGA : NVIDIA GeForce 960M 8106MB \\
Sistem Operasi : Windows 10 Home Single 64-bit \\
\hline
\end{tabular}

Berdasarkan uji coba akses halaman website pada ketiga perangkat komputer yang berbeda, halaman website dapat diakses dengan baik dan komponen yang ada pada masingmasing halaman berhasil ditampilkan. Sehingga dapat disimpulkan, aplikasi yang dibuat memenuhi aspek compatibility.

\section{Pengujian Usability}

Karakteristik ini mempresentasikan sejauh mana suatu produk atau sistem dapat digunakan oleh pengguna tertentu untuk mencapai tujuan tertentu dengan efektif, efisien, dan kepuasann dalam konteks tertentu [10]. Pengujian dilakukan dengan cara memberikan angket pertanyaan atau kuesioner. Pengujian dilakukan dengan cara menyebarkan angket pertanyaan pada responden untuk memberi penilaian terhadap aplikasi.

Adapun responden pada penelitian ini berjumlah 100 orang. Hasil dari penilaian kemudian dihitung menggunakan Skala Likert.

TABEL II

HASIL PENGUJIAN USABILITY

\begin{tabular}{|c|c|c|c|c|c|c|c|}
\hline \multirow{2}{*}{ No. } & \multirow{2}{*}{ Aspek } & \multicolumn{5}{|c|}{ Hasil Pengujian } & \multirow{2}{*}{$\begin{array}{c}\text { Persentase } \\
\text { Likert }\end{array}$} \\
\hline & & TB & KB & CB & B & SB & \\
\hline 1. & $\begin{array}{l}\text { Komponen } \\
\text { website } \\
\text { dapat dilihat } \\
\text { dengan jelas }\end{array}$ & 0 & 0 & 15 & 28 & 57 & $88,4 \%$ \\
\hline 2. & $\begin{array}{l}\text { Kombinasi } \\
\text { warna } \\
\text { menarik }\end{array}$ & 0 & 3 & 18 & 40 & 39 & $83 \%$ \\
\hline 3. & $\begin{array}{l}\text { Tombol } \\
\text { navigasi } \\
\text { berfungsi } \\
\text { baik }\end{array}$ & 0 & 0 & 19 & 39 & 42 & $84,6 \%$ \\
\hline 4. & $\begin{array}{l}\text { Denah } \\
\text { lokasi 3D } \\
\text { sudah } \\
\text { sesuai } \\
\text { dengan } \\
\text { kondisi asli } \\
\end{array}$ & 0 & 3 & 17 & 39 & 41 & $83,6 \%$ \\
\hline 5. & $\begin{array}{l}\text { Denah } \\
\text { lokasi 3D } \\
\text { dapat } \\
\text { memberikan } \\
\text { informasi } \\
\text { mengenai } \\
\text { lokasi } \\
\text { wisata }\end{array}$ & 0 & 1 & 15 & 30 & 54 & $87,4 \%$ \\
\hline 6. & $\begin{array}{l}\text { Denah } \\
\text { lokasi dapat } \\
\text { dijalankan } \\
\text { dengan baik }\end{array}$ & 0 & 0 & 21 & 36 & 43 & $84,4 \%$ \\
\hline 7. & $\begin{array}{l}\text { Denah } \\
\text { lokasi } \\
\text { cukup } \\
\text { menarik }\end{array}$ & 1 & 1 & 18 & 40 & 40 & $83,4 \%$ \\
\hline
\end{tabular}




\begin{tabular}{|c|c|c|c|c|c|c|c|}
\hline \multirow{2}{*}{ No. } & \multirow{2}{*}{ Aspek } & \multicolumn{5}{|c|}{ Hasil Pengujian } & \multirow{2}{*}{$\begin{array}{c}\text { Persentase } \\
\text { Likert }\end{array}$} \\
\hline & & TB & KB & CB & B & SB & \\
\hline 8. & $\begin{array}{l}\text { Virtual } \\
\text { Tour } \text { sudah } \\
\text { sesuai } \\
\text { dengan } \\
\text { kondisi asli }\end{array}$ & 0 & 0 & 18 & 36 & 46 & $85,6 \%$ \\
\hline 9. & $\begin{array}{l}\text { Virtual } \\
\text { Tour dapat } \\
\text { memberikan } \\
\text { informasi } \\
\text { mengenai } \\
\text { lokasi } \\
\text { wisata }\end{array}$ & 0 & 0 & 13 & 35 & 52 & $87,8 \%$ \\
\hline 10. & $\begin{array}{l}\text { Virtual } \\
\text { Tour dapat } \\
\text { dijalankan } \\
\text { dengan baik }\end{array}$ & 1 & 0 & 14 & 38 & 47 & $86 \%$ \\
\hline 11. & $\begin{array}{l}\text { Virtual } \\
\text { Tour cukup } \\
\text { menarik }\end{array}$ & 0 & 1 & 17 & 41 & 41 & $84,4 \%$ \\
\hline 12. & $\begin{array}{l}\text { Website } \\
\text { dapat } \\
\text { membantu } \\
\text { untuk } \\
\text { memperoleh } \\
\text { informasi } \\
\text { lokasi } \\
\text { wisata }\end{array}$ & 0 & 2 & 14 & 30 & 54 & $86,8 \%$ \\
\hline 13. & $\begin{array}{l}\text { Setelah } \\
\text { melihat } \\
\text { website, } \\
\text { apakah ada } \\
\text { keinginan } \\
\text { untuk } \\
\text { berkunjung }\end{array}$ & 1 & 2 & 32 & 23 & 42 & $80,6 \%$ \\
\hline
\end{tabular}

Berdasarkan hasil perhitungan penilaian oleh responden, didapat total persentase dari berdasarkan Skala Likert adalah $85,1 \%$. Setelah mengetahui nilai persentase, selanjutnya adalah mencari interval untuk mengetahui hasil akhir pengujian. Adapun persamaan yang digunakan adalah sebegai berikut:

I = $\mathbf{1 0 0} / \mathbf{5}=\mathbf{2 0}$

Nilai interval persentase adalah:

- $\mathrm{X}<=19,99 \%$ dikategorikan tidak baik

- $20 \%>=X<=39,99 \%$ dikategorikan kurang baik

- $40 \%>=X<=59,99 \%$ dikategorikan cukup baik

- $60 \%>=\mathrm{X}<=79,99 \%$ dikategorikan baik

- $X>=80 \%$ dikategorikan sangat baik

Dari interval persentase diatas dapat disimpulkan, penilaian responden pada aplikasi ini masuk dalam kategori sangat baik dengan total persentase $85,1 \%$, yang berarti aplikasi ini berhasil dibangun sesuai dengan tujuan.

\section{Pengujian Portability}

Suatu aplikasi dikatakan portable jika bisa diakses menggunakan browser yang berbeda, dari browser desktop maupun browser mobile [10]. Pengujian portability dilakukan dengan menjalankan aplikasi website di beberapa browser berbasis desktop dan mobile. Pengujian berfokus pada antarmuka yang dihasilkan pada halaman website. Berikut adalah hasil pengujian portability.

TABEL III

Hasil Pengujian Portability Desktop Browser

\begin{tabular}{|c|l|l|}
\hline No. & Nama Browser & Hasil Pengujian \\
\hline 1. & Google Chrome & $\begin{array}{l}\text { Komponen pada website berhasil } \\
\text { ditampilkan dengan baik }\end{array}$ \\
\hline 2. & Mozilla Firefox & $\begin{array}{l}\text { Komponen pada website berhasil } \\
\text { ditampilkan dengan baik }\end{array}$ \\
\hline 3. & Opera Mini & $\begin{array}{l}\text { Komponen pada website berhasil } \\
\text { ditampilkan dengan baik }\end{array}$ \\
\hline 4. & Internet Explorer & $\begin{array}{l}\text { Komponen pada website berhasil } \\
\text { ditampilkan dengan baik }\end{array}$ \\
\hline
\end{tabular}

TABEL IV

Hasil Pengujian PORTABILITy MobILE BRowSER

\begin{tabular}{|c|l|l|}
\hline No. & Nama Browser & Hasil Pengujian \\
\hline 1. & Android Browser & $\begin{array}{l}\text { Komponen yang ditampilkan pada } \\
\text { website mengalami gangguan, yaitu } \\
\text { pada halaman Virtual Tour dan 3D } \\
\text { Maps }\end{array}$ \\
\hline 2. & Chrome Mobile & $\begin{array}{l}\text { Komponen yang ditampilkan pada } \\
\text { website mengalami gangguan, yaitu } \\
\text { pada halaman Virtual Tour dan 3D } \\
\text { Maps }\end{array}$ \\
\hline 3. & Opera Mobile & $\begin{array}{l}\text { Komponen yang ditampilkan pada } \\
\text { website mengalami gangguan, yaitu } \\
\text { pada halaman Virtual Tour dan 3D } \\
\text { Maps }\end{array}$ \\
\hline
\end{tabular}

Berdasarkan pengujian portability yang dilakukan pada browser berbasis desktop, didapat seluruh komponen yang ada berhasil diakses dengan baik. Namun pada browser berbasis mobile, halaman Virtual Tour dan 3D Maps mengalami gangguan. Hal ini dikarenakan pada virtual tour, tombol yang digunakan tidak responsive pada resolusi layar mobile yang lebih kecil, karena merupakan bawaan dari aplikasi Tourweaver dan bukan komponen HTML. Sedangkan pada denah lokasi 3D, data yang diakses memiliki ukuran yang besar sehingga memakan waktu yang lama dan browser mengalami time out.

Dari pengujian ini dapat disimpulkan, bahwa aplikasi yang dibuat akan lebih baik jika diakses menggunakan browser berbasis desktop.

\section{F. Distribusi (Distribution)}

Pada tahap ini aplikasi yang telah selesai dibuat kemudian di publish menjadi file HTML5 yang akan dimasukkan ke website sehingga pengguna dapat mengakses aplikasi virtual tour dengan fitur 3D maps ini dengan menggunakan koneksi internet. Untuk pengunjung, website dapat diakses pada halaman "quburesort.virtualtour.ml". 


\section{KESIMPULAN}

Berdasarkan hasil analisis dan pengujian pada aplikasi yang telah dilakukan, maka dapat disimpulkan bahwa.

1. Aplikasi Virtual Tour dengan fitur 3D Maps ini dibangun berbasis website.

2. Hasil pengujian aplikasi adalah sebagai berikut.

a. Aplikasi yang dibuat berhasil diakses dengan baik dan komponen yang ada berhasil ditampilkan pada tiga perangkat yang berbeda. Sehingga dapat disimpulkan, aplikasi yang dibuat memenuhi aspek compatibility.

b. Berdasarkan hasil penilaian responden, didapat aplikasi yang dibuat dinilai sangat baik total persentase $85,1 \%$ berdasarkan pengukuran dengan Skala Likert.

c. Berdasarkan pengujian portability yang dilakukan dengan cara mengakses website pada browser berbeda berbasis desktop dan mobile, didapat bahwa aplikasi dapat berjalan dengan baik pada browser berbasis desktop. Sedangkan untuk browser mobile, didapat gangguan pada halaman yang memuat denah lokasi 3D dan virtual tour. Sehingga dapat disimpulkan bahwa aplikasi ini lebih baik jika diakses menggunakan browser berbasis desktop.

\section{REFERENSI}

[1] Kurniati, Intania., Alkautsar, Mochamad., Dharmawan, Anthony. 2010. Analisis dan Perancangan Aplikasi Virtual Tour Museum di Kawasan Taman Fatahillah Berbasis Multimedia bagi Unit Pelaksana Teknik Kota Tua Jakarta. Jakarta: Skripsi Teknik Informatika, Universitas Bina Nusantara.

[2] Harianto. 2016. Rancang Bangun Aplikasi Virtual Tour Museum Provinsi Kalimantan Barat Untuk Edukasi Sejarah. Jurnal Teknik Informatika Universitas Tanjungpura.

[3] Handjojo, Fania Valentina. 2013. Perancangan dan Implementasi Aplikasi Content Management System dengan Format Virtual Online Tour. Jurnal Teknik Informatika Universitas Tanjungpura.

[4] Panggabean, Rio Fiorido. 2015. Rancang Bangun Peta Virtual 3D Kampus UNTAN dengan Fitur Panorama $360^{\circ} \times 180^{\circ}$. Jurnal Teknik Informatika Universitas Tanjungpura.

[5] Yudhianto, Tri. 2014. Aplikasi Peta Tiga Dimensi Kampus Universitas Widyatama. Bandung: Tugas Akhir Program Studi Teknik Informatika, Fakultas Teknik, Universitas Widyatama.

[6] Sutopo, Ariesto Hadi. 2003. Multimedia Interaktif dengan Flash. Yogyakarta: Graha Ilmu.

[7] Ariani, Rizka. 2012. Desain Arsitektur Sistem Informasi Penjualan Polis Asuransi Jiwa Berbasis Web Pada PT. Asuransi Jiwa XYZ. Jakarta: Thesis Sistem Informasi, Universitas Bina Nusantara.

[8] Irawan, Anggi., Wijaya, Frendy. 2008. Analisis dan Perancangan Aplikasi Poling dan Kuis Melalui Short Message Service (SMS) Menggunakan Metode SMS Gateway (Studi Kasus: PT. Indonusa Telemedia). Jakarta: Skripsi Universitas Bina Nusantara.

[9] Setiawan, Heru., Jati. Handaru. 2017. Analisis Kualitas Sistem Informasi Pantauan Pembentukan Karakter Siswa di SMK N 2 Depok Sleman. Yogyakarta: Jurnal Elinvo (Electronics, Informatics, and Vocational Education), Volume 2, Nomor 1, Mei 2017.

[10] Ahkamiyati, Zumrotul. 2016. Pengembangan dan Analisis Kualitas Sistem Informasi Bimbingan Tugas Akhir Skripsi Online untuk Mahasiswa Tingkat Akhir Pendidikan Teknik Informatika FT UNY. Yogyakarta: Skripsi Program Studi Pendidikan Teknik Informatika, Universitas Negeri Yogyakarta. 